CONGENITAL

HEART DISEASE

\title{
Understanding the epigenetic origins of congenital heart disease may lead to its control
}

Rik De Decker

Division of Cardiology, Department of Paediatrics and Child Health, University of Cape Town and Red Cross War Memorial Children's Hospital, Cape Town, South Africa

Address for correspondence:

Dr Rik De Decker

Department of Paediatrics and Child Health

University of Cape Town

Red Cross War Memorial Children's Hospital

Klipfontein Road

Rondebosch

7700

South Africa

Email:

rik.dedecker@uct.ac.za

\section{INTRODUCTION}

"There is no use trying," said Alice, "one can't believe impossible things."

"I dare say you haven't had much practice," said the Queen. "When I was your age, I always did it for half an hour a day. Why, sometimes I've believed as many as six impossible things before breakfast."

Lewis Carroll: Through the Looking Glass ( 87 I)

It is well established that the birth incidence of congenital heart disease (CHD) is 8 per I 000 live births, with some variation within, and between populations. ${ }^{(1)}$ In developing countries, this incidence is higher and is set at 1\%.(2) The Global Report on Birth Defects ${ }^{(3)}$ puts CHD as the most common genetic, or genetic-related, birth defect accounting for more affected newborns than the subsequent 4 commonest defects put together. ${ }^{(4)}$ It is also known that socio-economic profiles may affect this incidence, with an inverse relationship between socio-economic status and all birth defects, including $\mathrm{CHD} .{ }^{(5)}$ Approximately $60 \%$ of babies born with CHD will require an intervention (cardiac surgery or percutaneous catheterisation intervention) at some time, and half of these (3/I 000) will have critical (usually duct-dependent) CHD, and will need intervention in the neonatal period to avoid death or severe morbidity. ${ }^{(4,6)}$

This article will introduce epigenetics and its role in the control of the expression of developmental genes. It will then show

\section{ABSTRACT}

Congenital heart disease (CHD), which occurs in about I per 100 live births, remains the leading life-threatening abnormality present at birth. It is reasonable to assume that most, if not all, CHD stems from errors or disruptions in the genetic control of heart development, and that a more thorough knowledge of these controlling molecular mechanisms may lead to a better understanding of the origins of CHD. With understanding comes the potential for prevention, and possibly early repair.

Our operational research in the Western Cape has identified a severe epidemiological shortfall between the theoretical number of newborns that should present to us with severe CHD and those who actually do - we are referred only $\mathbf{5 0} \%$ of the children that (epidemiologically) should receive heart surgery. Even if we could identify all the missing children, our services would be unable to contend with the consequent demand. This stark dilemma plays itself out in most resource-constrained cardiac health services.

It is therefore of utmost importance that the origins of CHD that may be under environmental influences - "the epigenetic causes of CHD" - are prioritised in our quest to reduce heart defects. I will outline these influences and show how an understanding of them may begin to reduce an enormous health burden. SAHeart 2016;13:90-96

how perturbations in the epigenetic milieu are easily acquired and how they may increase the risk of $\mathrm{CHD}$ under certain circumstances. However, a thorough understanding of the epigenetic control of cardiogenesis implies an exciting new prospect namely that the environmental factors known to alter epigenetic mechanisms are potential targets for manipulating the control of heart development - either by reducing exposure to known cardiac teratogens, or increasing exposure to those factors known to reduce the incidence of CHD.

\section{EPIDEMIOLOGY OF CHD IN THE WESTERN \\ CAPE, SOUTH AFRICA: A CONUNDRUM}

The Paediatric Cardiology Service of the Western Cape (PCSWC), based at the Red Cross War Memorial and Tygerberg Children's Hospitals in Cape Town, serves the public health paediatric cardiology needs of the Western Cape, South Africa. Using the CHD incidences as given before, we could estimate the theoretical epidemiological demands on this service. During 2012, 93394 newborn babies were recorded in the public health sector (Stefan Gebhardt, pers. comm). From 
this we can estimate (Figure I) that the number of newborns requiring cardiac intervention is approximately 558 cases annually (of which 229 would be "critical" CHD). All paediatric cardiac surgery of the PCSWC (and therefore all paediatric cardiac surgery in the public health sector of the Western Cape) is performed at Red Cross Hospital only, but the total number of cases done rarely exceeds 300 per annum. This number includes staged operations (i.e. one in a series required by that patient, for example leading to a Fontan procedure), re-do operations, and patients from outside the Western Cape. Therefore, we estimate that a minimum of 250 new cases ( $\pm 558-300)$ are missed in the Western Cape annually, but realistically, this figure is closer to 300 cases. Naturally, the backlog increases over time, accumulating those cases that survive the early critical period.

The conundrum arises as a result of 2 major problems: firstly the poor recognition of children (particularly newborn babies) with $\mathrm{CHD}$ and secondly the limitation of service delivery due to public health sector resource constraints. This situation is not unique to the Western Cape, but common worldwide, particularly so in countries with resource-limited health care systems. ${ }^{(7)}$

However, it should be recognised that effective ascertainment and efficient service delivery can reduce the prevalence of
$\mathrm{CHD}$, but not its incidence. It may therefore be important to start focusing on alternative strategies to reduce the incidence of $\mathrm{CHD}$. Is this at all possible?

\section{THE AETIOLOGICAL LANDSCAPE OF CONGENITAL HEART DISEASE}

Many associations between well-defined genetic conditions and heart defects are known. ${ }^{(8)}$ The most common (Figure 2) are those of chromosomal defects linked to a specific set of heart defects. Some examples include Down syndrome with endocardial cushion defects, the 22q11.2 deletion syndrome with conotruncal lesions, Turner syndrome with coarctation of the aorta, and Williams syndrome with pulmonary and aortic root stenosis. In addition, there are many conditions caused by single gene mutations known to be associated with a limited suite of heart defects, such as Marfan syndrome (fibrillin gene mutation) with mitral valve and aortic root dilatation, Alagille syndrome (Jagged-I gene mutation) with tetralogy of Fallot, and Noonan syndrome (PTPNII gene mutation) with pulmonary stenosis and hypertrophic cardiomyopathy. While these are frequent associations, the "usual or characteristic" lesions are not invariably present. Indeed, only 49\% of children with Down syndrome will have associated $\mathrm{CHD}^{(9)}$ and a child with, for example, Alagille syndrome will not invariably have a right ventricular outflow tract lesion. Furthermore, there are many

\section{The epidemiology of CHD in the Western Cape with an estimate of the case load}

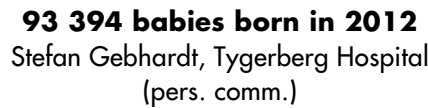

93394 babies born in 2012 (pers. comm.)

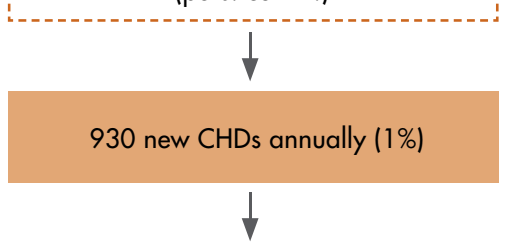

\section{$558(60 \%)$ will need cardiac surgery at some point}



RXH only does $\pm \mathbf{3 0 0}$ cardiac procedures on WC patients per year (which includes redo and staged operations)

Epidemiologically, 558 children are predicted to require surgery annually at RXH.

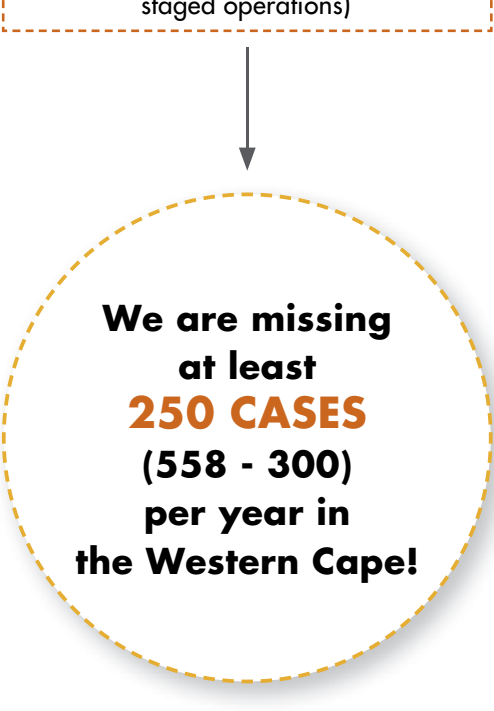




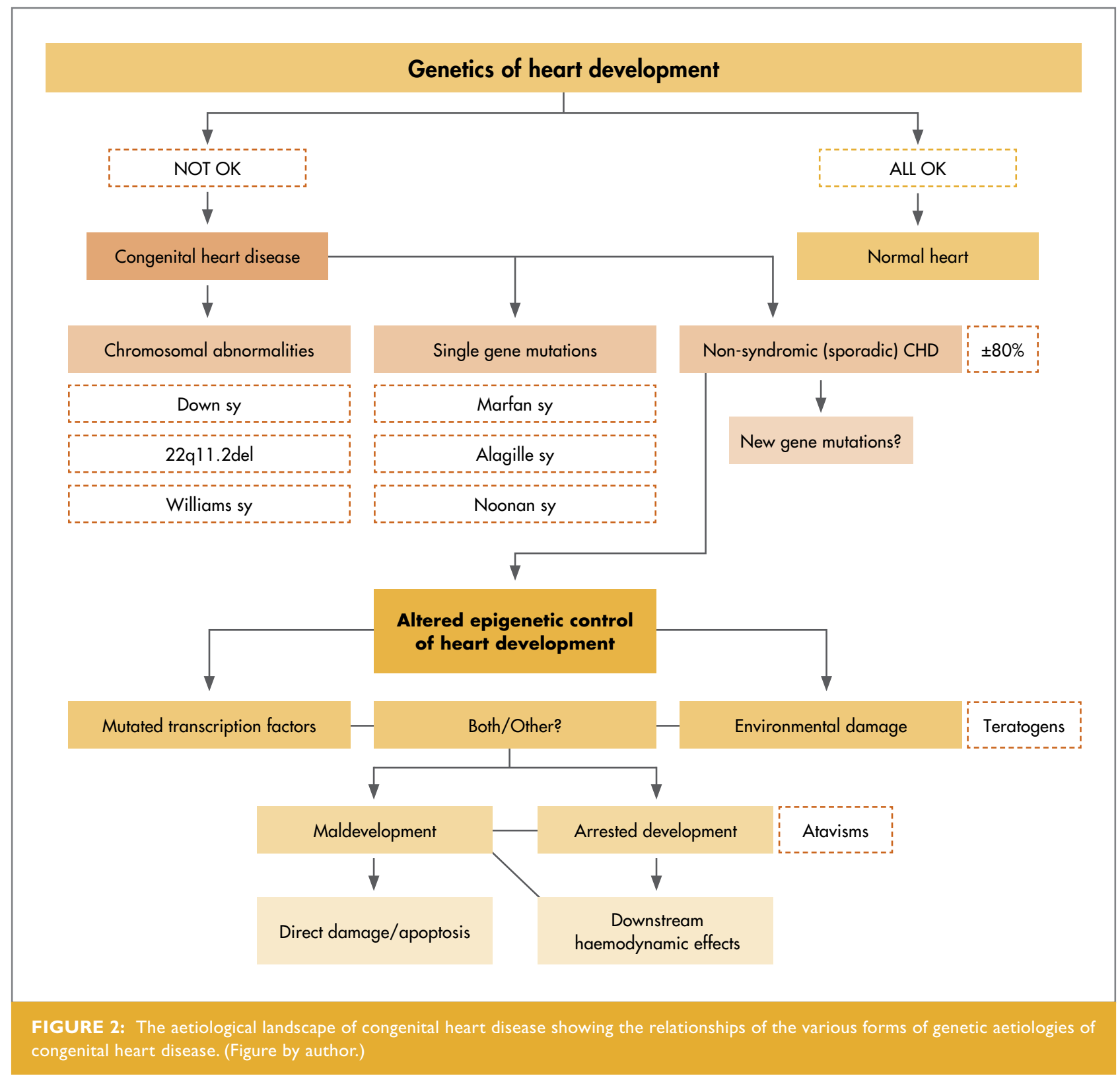

novel associations between children with, as yet, undefined dysmorphism with extracardiac comorbidities that may be associated with any of a large number of heart lesions.

Added together, these associations of CHD, with known genetic syndromes and other lesser or unknown dysmorphic conditions, account for only $20 \%$ of children born with CHD. ${ }^{(8,10)}$ In the majority, the heart defect is solitary (or sporadic), thus the only congenital defect in a non-syndromic child with no known family history. Until recently these heart defects have posed an enigma: what is the exact cause of the isolated heart lesion when a search for a causative gene often proves to be futile? The lesion may be a common one (e.g. VSD, tetralogy of Fallot or ASD) yet it is usually fruitless to search for a mutated gene, and an extended family tree or cascade screening may be pointless. In addition, the recurrence risk for the children of survivors of isolated CHD surgery is unpredictable, and is empirically set at $3-5 \%$ (depending on the lesion), but this prediction cannot be made with any certainty as in the case of dominant or recessive genetic transmission patterns.

\section{THE GENETIC CAUSES OF CHD}

Despite this uncertainty, Helen Taussig's contention (1) remains highly probable that nearly all CHD stems from errors during the genetic control of embryonic heart development, if not by direct genetic alteration, then by changes to the controlling elements of normal genes that result in an altered phenotype. ${ }^{(4,12)}$ Cardiac embryogenesis is an extremely complex process, but recently rapid and astounding developments have 
occurred in gene discovery, in the detailed descriptions of the embryology of model organisms, in the elucidation of the causative genetic mechanisms in many known cardiogenetic syndromes, and following the full sequencing of the (proteinexpressing) human genome in 2003. This progress has allowed huge strides to be made in elucidating the causes of many CHDs. However, this success has rapidly exposed and emphasised the unknown and, until very recently, the cause(s) of isolated CHD has remained obscure.

It is only with the very recent onset of studies into human epigenetics that it has become possible to speculate, with more evidence, as to the causes of the common non-syndromic and isolated heart lesions. ${ }^{(8)}$ The crux lies in the realisation that it may be the control of heart development that is perturbed, rather than the structural, protein-coding genes per se.

\section{WHAT IS EPIGENETICS AND WHAT ROLE DOES IT PLAY IN HEART DEVELOPMENT?}

A detailed description of the rapidly burgeoning field of epigenetics and its fundamental role in embryogenesis is beyond the scope of this article, but a brief outline of its importance in cardiogenesis follows.

In 2011 Gottesfeld(13) wrote: "Each cell type in an organism expresses a distinct set of genes... but all cells have the same DNA or genes. A fertilised egg, or zygote, changes into the numerous cell types of an organism... by the programmed expression or repression of classes of genes." Epigenetics is therefore the combination of all the mechanisms that control the expression of the genes involved in the normal development of all tissues and organs, be they DNA sequences that code for structural proteins, or those that code for regulatory proteins such as transcription factors. Only the coding DNA sequences (or roughly 21000 genes) of these proteins were elucidated by the Human Genome Project in $\left.200\right|^{(14,15)}$ and they form only approximately $3 \%$ of the entire DNA complement in each cell. ${ }^{(16)}$ Much of the remaining DNA contains regulatory elements, or conserved non-coding elements, ${ }^{(17)}$ that control the expression of the coding DNA at the exact time and in precisely the correct sequence and amounts. These are the "factors and processes around DNA that regulate genome activity independent of the DNA sequence and that are mitotically and meiotically stable", as Skinner ${ }^{(18)}$ defined epigenetics in 2011 .

Genes are inheritable, and as building blocks they are passed on unchanged to progeny, unless they are mutated during gametogenesis, thereby potentially causing a genetic problem which may, or may not, cause congenital defects. But in addition, the epigenetic, controlling factors are also inheritable in a stable way to continue their process of expression control in the offspring. Thus, another and more recent definition ${ }^{(19)}$ of epi-genetics is "the changes in the regulation of gene expression that can be passed on to a cell's progeny but are not due to changes to the nucleotide sequence of the gene."
Language is a useful analogy to help understand epigenetic mechanisms. Think of a language as a system which is built up of only 26 letters of the alphabet which make words (as genes). These words themselves, and their uses, are governed by the fundamental rules of spelling and grammar (the epigenetic factors) that remain unseen in written and spoken language.

However, the epigenetic factors themselves are not immune to damage and alteration ${ }^{(20)}$ but are changeable, being sensitive and alterable by many environmental factors. The transcription factors may be mutated, thereby altering their controlling effects, or direct environmental damage to epigenetic factors may occur. These altered influences or damaged control regulation of gene expression may either cause cardiac lesions by maldevelopment (e.g. a VSD) or by arrested normal development of the heart, the so-called atavisms or heart development stopped at a phase that would be normal for an evolutionary predecessor, ${ }^{(21)}$ e.g. the 3-chambered heart of a frog, or the septal defects of a reptile. (22) Furthermore, such lesions have significant "downstream" haemodynamic effects with serious anatomical sequelae, such as hypoplastic pulmonary arteries, or severe pulmonary hypertension.

In our language analogy, all English language speakers use the same alphabet, but environmental influences create major differences between Oxford English and the English spoken in Australia, America, or Jamaica. Furthermore, the same alphabet is dramatically altered by the environment to form the words of different languages, such as French, German or Danish. But only the native speakers will realise (and sometimes understand) the mistakes when those who do not obey the spelling or grammar rules damage their language. Similarly, we should search for the epigenetic factors that incorrectly control the expression of structural and controlling genes and thereby cause cardiac maldevelopment or atavisms.

Skinner(18) commented that: "The paradigm that genetics is the primary factor to regulate developmental biology is limited and ignores the plasticity to respond rapidly to environment, nor does it explain abnormal development and disease etiology in the absence of genetic alterations" (my emphasis). These insights, and others akin to it, begin to give concrete meaning to Taussig's ${ }^{(11)}$ remarkable foresight that understanding the molecular mechanisms of heart development may allow us to understand CHD. The crux of these comments is that with the understanding of aetiology and pathogenesis, the possibility arises to (a) recognise and avoid pathogenic environmental triggers, or (b) manipulate epigenetic controls to achieve reductions in errors of cardiac maldevelopment.

\section{IMPORTANT ENVIRONMENTAL FACTORS IN CHD PATHOGENESIS}

The importance of environmental influences on the aetiology of $\mathrm{CHD}$ has long been recognised. It formed one of the central investigations of one of the most fundamental and influential studies into the epidemiology of CHD, the Baltimore- 
Washington Infant Study (BWIS).(23) Their fundamental hypothesis included an assessment of the contributions of environmental exposure, exposure route and genetic susceptibility to congenital abnormalities at birth. When one considers that this work was done before the era of genomics in the current millennium, their goals seemed very ambitious, but it nevertheless made many valuable contributions to this field. ${ }^{(24)}$

Since the BWIS, many extensive studies of nongenetic (environmental) factors influencing the incidence of $\mathrm{CHD}$ have been performed. ${ }^{(25)}$ Patel and Burns ${ }^{(26)}$ summarised these in a metaanalysis in 2013. Figure 3 summarises the most significant environmental factors from their study in terms of the most significant odds ratios for the risk of CHD. Note that most are common environmental factors that are amenable to targeted strategies for risk reduction. Trichloroethylene had an OR of as high as 14.5 for inducing cardiac lesions, and this is one of the reasons its use has been abandoned.

However, despite compiling these large studies of associations and the high relative risks of some known environmental risk factors for CHD, few significant advances have been made in understanding their precise aetiological mechanisms. Understanding these well will better substantiate motivations for the implementation of strategies to reduce exposure to known pathogenic risk factors. Epigenetics provides the causal link to the environmental influence of genetic regulation ${ }^{(27)}$ - this helps to deconstruct the nature, nurture contradistinction and begins to remove its facile dichotomy.

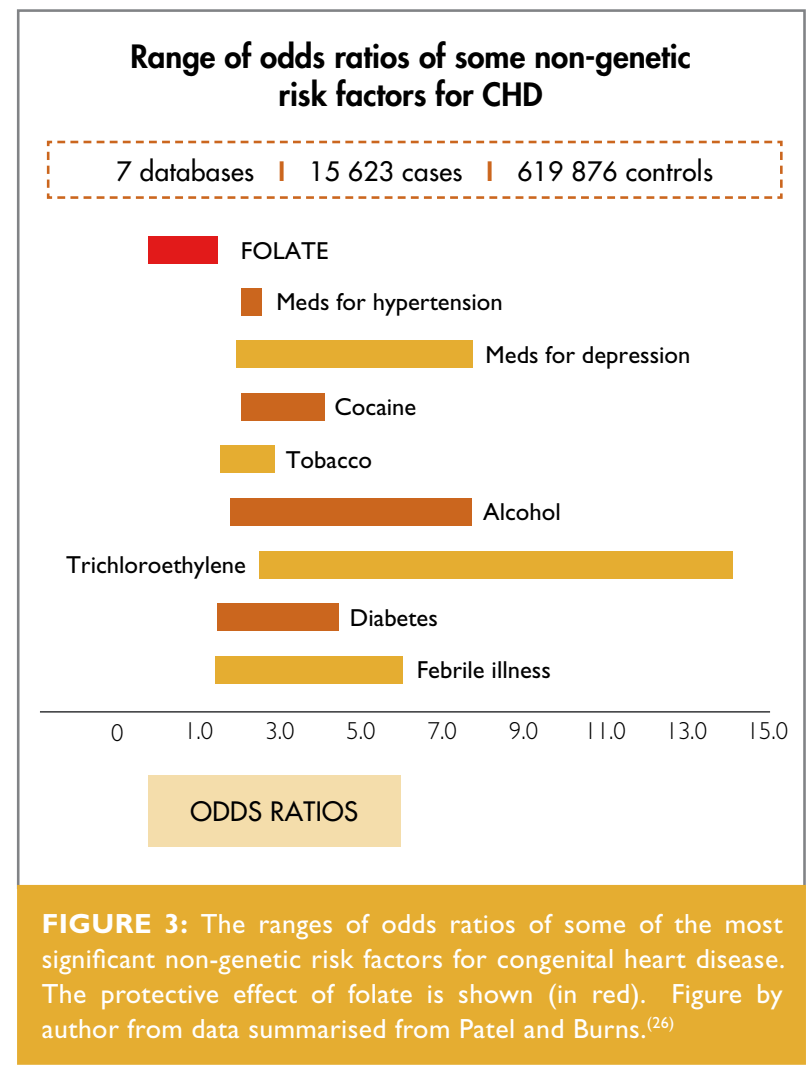

\section{ALCOHOL EXPOSURE: EVIDENCE FOR EPIGENETIC DAMAGE}

Evidence from molecular biology corroborates these epidemiological associations. An environmental risk factor that has been well studied is alcohol; periconceptional exposure to ethanol has become one of the best studied teratogens in fetal alcohol spectrum disorders. ${ }^{(28)}$

In mouse models of fetal alcohol syndrome disorders, alcohol exposure induced aberrant changes in DNA methylation patterns with associated changes in gene expression. ${ }^{(29)}$ Evidence has also been found to suggest that chronic alcohol use demethylates normally hypermethylated regions in sperm DNA. ${ }^{(30)}$ This illustrates how environmental changes to the epigenome may become transgenerational. Such studies have highlighted the importance of paternal teratogen exposure to increasing risk of cardiac maldevelopment of offspring.

\section{THE PROMISE OF FOLATE: EVIDENCE FOR EPIGENETIC PROTECTION}

In 2009, lonescu-lttu, et al. ${ }^{(31)}$ published a landmark epidemiological study of the incidence of severe CHD in Quebec, Canada, before and after the implementation of mandatory folic acid fortification of grain products in Canada in 1998. The time trend analysis revealed a significant year-on-year reduction in the incidence of severe CHD (6.2\% per year over 5 years) after 1998. This powerfully associated an increase in an environmental factor (folate) with reduction in the risk of newborn CHD.

Subsequent studies, such as those in the Netherlands by Van Beynum, et al. in 2010,(32) have substantiated these findings epidemiologically. A meta-analysis of 18 studies, published in $2015,{ }^{(33)}$ has provided evidence that maternal folate supplementation is associated with a decreased risk of CHDs (Relative risk: $0.72,95 \% \mathrm{Cl}: 0.63-0.82$ ). They describe this as providing "robust" evidence of the positive effect of maternal folate fortification and reduced risk of CHD.

Fortification of staple foods with folate was introduced in South Africa in October 2003, resulting in a $30.5 \%$ reduction in the

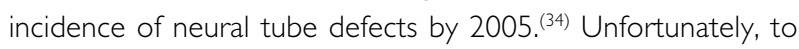
date, no studies of the incidence of $\mathrm{CHD}$ has been undertaken in South Africa, and it is not known whether the folate fortification in 2003 has subsequently had an impact on the incidence of CHD.

Work by several groups has shown associations between gene variants in the folate metabolic pathway and an increased risk for $\mathrm{CHD}$, but specifically associated with the group of conotruncal defects. ${ }^{(35)}$ On the other hand, a large and comprehensive assessment $^{(36)}$ of the relationship between left-sided cardiac defects and folate-related genes has shown little evidence that the origins of left-sided heart defects, such as hypoplastic left 
heart syndrome, coarctation of the aorta, bicuspid aortic valve, aortic valve stenosis or isolated mitral valve anomalies, are folate related.

\section{ENVIRONMENT-EPIGENETIC INTERACTION}

It has become clear that chemical changes in, and around, cells may affect the epigenetic control of genes by triggering alterations in the way genes are switched on or off. ${ }^{(37)}$ Such chemical influences may even include diet, stress levels and prenatal nutrition or care. ${ }^{(38)}$ Some of the best-studied alterations are those that activate epigenetic marks that modify the production of proteins, such as histones. ${ }^{(39)}$ In the USA, the Environmental Protection Agency has identified known teratogenic substances of which the most harmful are lead, mercury, cocaine, alcohol, tobacco, heroin, iodized radiation and dioxin. ${ }^{(40)}$ Fetal development is altered by these common teratogens due to the permanent epigenetic changes in the structure and control of genes.

As far back as 1987, the paleontologist Stephen Jay Gould(41) wrote that "we must seek to understand the emergent and irreducible properties arising from an inextricable interpenetration of genes and environment." While, strictly speaking, he was not writing about congenital defects, he was arguing for a reassessment of the ingrained notion of genetics and environment being completely separate influences on social biology. Margaret Lock, a Canadian anthropologist, takes this argument further, but within the medical realm, as she argues for the abolishment of the false assumption of a rigid distinction between nature and nurture. She writes ${ }^{(42)}$ cogently that "epigenetic findings strongly suggest that history, politics, social environments, racism, and discrimination must be given consideration equal to or greater than that of the immediate family circumstances, thus posing challenging questions for the location of responsibility for ill health" (my emphasis). She goes on to point out that epigenetics introduces the notion that "your behaviour" may generate malformations in your children and grandchildren!

To this we may add our responsibility to apply the increasing evidence from these new epigenetic insights, firstly to reduce periconceptual exposure to high-risk epigenetic factors, as mentioned above, and secondly to better advocate proven protective factors, such as periconceptual folate supplementation, to minimise the risk further. It should be our behaviour to inform and guide those at highest risk of inducing epigenetic causes of malformations to their progeny.

\section{CONCLUSION}

We must realise that termination of pregnancy, medication, interventional catheterisation, and cardiac surgery are not our only methods to combat children's heart disease. Epidemiology has elucidated mechanisms whereby epidemiological suspicions may, in time, be substantiated as aetiological certainty, opening the potential for well-informed, evidence-based prevention (or possibly early correction) of congenital heart disease. However, wider perspectives from epigenetics indicate that we should also focus on ameliorating the social triggers and precedents of cardiac maldevelopment.

Epigenetics has now clearly been shown to play an important role in the control of the expression of developmental genes. It is also known that perturbations in the epigenetic milieu are easily acquired from many environmental and social factors that may increase the risk of CHD. The precise mechanisms of action of many, perhaps most, of these environmental influences on the control of developmental genes remain to be elucidated. Understanding these epigenetic influences on cardiac embryogenesis may suggest targets for manipulating the control of heart development. With clear insight into its aetiology, we may begin to dream of the ways to reduce the incidence of $\mathrm{CHD}$. ${ }^{(8)}$ But here is an exciting new prospect that we, as clinicians, should advocate: to encourage the further elucidation of those factors in the social environments of our patient populations that may be deleterious to heart development, and encourage the introduction of proven factors that reduce the incidence of CHD. In a resource-limited society, social upliftment may be our strongest epigenomic medicine!

"DNA, we thought, was an iron-clad code that we and our children and their children had to live by. Now we can imagine a world in which we tinker with DNA, bend it to our will."(38)

\section{Conflict of interest: none declared.}




\section{REFERENCES}

I. Hoffman JIE. Incidence of congenital heart disease: I. Postnatal incidence. Paediatric Cardiology 1995; 16:103-11.

2. Hoffman JIE, Kaplan S. The incidence of congenital heart disease. J Am Coll Cardiol 2002;39:1890-1900.

3. Christianson A, Howson CP, Modell B. March of Dimes global report on birth defects. New York: March of Dimes Birth Defects Foundation; 2006.

4. Webber DM, MacLeod SL, Bamshad MJ, et al. Developments in our understanding of the genetic basis of birth defects. Birth Defects Res A Clin Mol Teratol. 2015 Aug; 103(8):680-91.

5. Yu D, Feng $Y$, Yang $L$, et al. Maternal socioeconomic status and the risk of congenital heart defects in offspring: A Meta-Analysis of 33 Studies. PLoS One 2014; 9(I0): el I I056.

6. Martin GR, Beekman RH, Mikula EB, et al. Implementing recommended screening for critical congenital heart disease. Paediatrics 2013 Jul; I32(1): el 85-92.

7. Kumar RK. Delivering paediatric cardiac care with limited resources. Ann Pediatr Cardiol 2014 Sep-Dec;7(3):163-166.

8. Gelb BD, Chung WK. Complex genetics and the aetiology of human congenital disease. Cold Spring Harb Perspect Med 2016; 4(7):epub ahead of print.

9. Roussot MA, Lawrenson JB, De Decker HP, et al. Is cardiac surgery warranted in children with Down syndrome? A case-controlled review. S Afr Med J 2006;96:924-930

10. Edwards J), Gelb BD. Genetics of congenital heart disease. Curr Opin Cardiol. 2016;31:epub ahead of print.

II. Taussig HB. Evolutionary origin of cardiac malformations. JACC 1989;12(4): 1079-46.

12. Oyen N, Poulsen G, Boyd HA, et al. Reccurrence of congenital heart disease in families. Circulation 2009; 120:295-301.

13. Gottesfeld JM. Introduction to the Thematic Minireview Series on Epigenetics. The Journal of Biological Chemistry 201 1;286(21): 18345-18346.

14. International Human Genome Sequencing Consortium. Initial sequencing and analysis of the human genome. Nature 200 1;409: 860-921.

15. Venter JC, Adams MD, Myers EW, et al. The sequence of the human genome. Science 200 I;291:1304-1351.

16. Pennisi E. ENCODE project writes eulogy for junk DNA. Science 20 I2;337: |159-||6|.

17. Woolfe A, Goodson M, Goode DK, et al. Highly conserved non-coding sequences are associated with vertebrate development. PLoS Biol 2005; 3(1):e7.

18. Skinner MK. Role of Epigenetics in developmental biology and transgenerational inheritance. Birth defects research (Part C) 201 1;93:51-55 p.52.

19. Editorial (no author given). Nature 20।5;5।8:273.

20. Zaidi S, Choi M, Wakimoto $\mathrm{H}$, et al. De novo mutations in histone-modifying genes in congenital heart disease. Nature 2013;498:220-224.

21. Moorman AFM, Christoffels VM. Cardiac chamber formation: Development, genes, and evolution. Physiol Rev 2003;83:1 223-1267.

22. Sklansky MS, Levy DJ, Elias WT, et al. Reptilian echocardiography: Insights into ontogeny and phylogeny? Echocardiography 200 I; 18(6):531-533.

23. Nies M, Brenner Jl. Tetralogy of Fallot: Epidemiology meets real-world management: Lessons from the Baltimore-Washington Infant Study. Cardiology in the Young 2013;23:867-870.

24. Loffredo, CA. 2000. Epidemiology of cardiovascular malformations: prevalence and risk factors. American Journal of Medical Genetics 97:319-325.

25. Vecoli C, Pulignani S, Foffa I, et al. Congenital heart disease: The crossroads of genetics, epigenetics and environment. Current Genomics 2014; 15:390-399.

26. Patel SS, Burns TL. Non-genetic risk factors and congenital heart defects. Pediatr Cardiol 2013;34:1535-1555.
27. Choudhuri S, Cui Y, Klaassen CD. Molecular targets of epigenetic regulation and effectors of environmental influences. Toxicology and Applied Pharmacology 2010;245:378-393.

28. Ramsay M. Genetic and epigenetic insights into fetal alcohol spectrum disorders. Genome Medicine 2010;2:27-35.

29. Liu Y, Balaraman Y, Wang G, et al. Alcohol exposure alters DNA methylation profiles in mouse embryos at early neurulation. Epigenetics 2009;4:500-51।.

30. Zhou FC, et al. Alteration of gene expression by alcohol exposure at early neurulation. BMC Genomics 201 1; 12:124.

31. Ionescu-Ittu R, Marelli AJ, Mackie AS, et al. Prevalence of severe congenital heart disease after folic acid fortification of grain products: Time trend analysis in Quebec, Canada. BMJ 2009;338:bI673.

32. Van Beynum IM, Kapusta L, Bakker MK, et al. Protective effect of periconceptional folic acid supplements on the risk of congenital heart defects: a registry-based case-control study in the northern Netherlands. European Heart Journal 20 10;31:464-47I.

33. Feng $\mathrm{Y}, \mathrm{W}$ ang $\mathrm{S}$, Chen $\mathrm{R}$, et al. Maternal folic acid supplementation and the risk of congenital heart defects in offspring: A meta-analysis of epidemiological observational studies. Scientific Reports 2015;5:8506.

34. Sayed AS, Bourne D, Pattinson R, et al. Decline in the prevalence of neural tube defects following folic acid fortification and its cost-benefit in South Africa. Birth Defects Res A Clin Mol Teratol. 2008;82(4):21 I-216.

35. Lupo PJ, Goldmuntz E, Mitchell LE. Gene-Gene Interactions in the folate metabolic pathway and the risk of conotruncal heart defects. Journal of Biomedicine and Biotechnology 2010;2010:1-7.

36. Mitchell LE, Long J, Garbarini J, et al. Variants of folate metabolism genes and risk of left-sided cardiac defects. Birth Defects Res A Clin Mol Teratol 20 I 0; 88(1):48-53.

37. Issa, J-P. NOVA. (2007). From PBS: Epigenetic Therapy (online). Retrieved February 21, 2016. http://www.pbs.org/wgbh/nova/genes/issa.html

38. Cloud J. (2010). Why your DNA isn't your destiny. Time. (online). Retrieved February 21, 2016. http://www.time.com/time/printout/0,8816, | 9523 | 3,00.html.

39. Bygren LO. Intergenerational health responses to adverse and enriched environments. Annu Rev Public Health. 2013;34:49-60.

40. Kellerman T. 2006. Evironmental Teratogens and Neurobehavioral Disorders in Persons with Developmental Disabilites. Washington DC: US Environmental Protection Agency.

41. Gould SJ. An Urchin in the Storm: Essays about Books and Ideas. WW Norton. 1987.

42. Lock M. The lure of the epigenome. The Lancet 2013;381:1896-7. 